УДК 81.00

DOI: 10.18101/2305-459X-2019-4-34-38

\title{
ЗРИТЕЛЬНОЕ ВОСПРИЯТИЕ КАК ПСИХОФИЗИОЛОГИЧЕСКАЯ ОСНОВА ОБЪЕКТА ТЕКСТА ТИПА «ОПИСАНИЕ»
}

\author{
(C) Смирнова Светлана Игоревна \\ кандидат филологических наук, старший преподаватель, \\ Бурятский государственный университет им. Д. Банзарова \\ Россия, 670000, г.Улан-Удэ, ул. Сухэ-Батора, 16 \\ E-mail: s.petenko@yandex.ru
}

Статья посвящена изучению психофизической основы описательных текстов. В ходе исследования рассматриваются особенности процесса зрительного восприятия объектов действительности, а также раскрывается соответствие воспринятых центральным типом зрения составляющих структурно-семантического каркаса описательного текста пространственным параметрам объектов действительности. Автор рассматривает строение зрительного анализатора, а именно центральный и периферический отделы, отвечающие за получение разных импульсов из внешнего мира, а также непосредственно процесс зрительного восприятия объектов. В статье раскрываются особенности восприятия объектов действительности центральным типом зрения. Выясняется, что центральное зрение позволяет констатировать наличие объектов, разглядеть их форму, размер и цветовые характеристики. Воспринятая центральным типом зрения предметность пространства находит свое вербальное отражение в тексте типа «описание», структурно-семантическим каркасом которого выступает актантное ядро.

Ключевые слова: описательный текст; восприятие; зрительный анализатор; центральное и периферическое зрение; центральный тип зрения; фоторецепторы; структурно-семантический каркас; объект речи; актантное ядро; признаковые слова;

Для цитирования:

Смирнова С. И. Зрительное восприятие как психофизиологическая основа объекта текста типа «описание» // Вестник Бурятского государственного университета. Язык. Литература. Культура. 2019. Вып. 4. С. 34-38.

В формальной логике тексты подразделяются на тексты констатирующего типа и тексты типа «рассуждение». К констатирующим типам текста ученые относят «описание» и «повествование». Описательный текст передает «фрагменты действительности в их статике», повествовательный текст «излагает события в их развитии во времени» [Хамаганова, 2002, с. 22]. Предмет в широком понимании выступает объектом речи в описании, в повествовательном тексте объектами речи являются сменяющие друг друга события [Нечаева, 1975, с. 13].

Наибольший интерес для настоящего исследования представляет описательный текст. В описательном тексте, как известно, вербализуются пространственные характеристики бытия, то есть окружающая действительность. Объекты окружающей действительности передаются в тексте через их признаки. Психофизиологической основой объектов проанализированных нами описательных текстов выступают пространственные характеристики бытия, воспринятые центральным отделом зрительного анализатора. 
С. И. Смирнова. Зрительное восприятие как психофизиологическая основа объекта текста типа «описание»

Рассмотрим процесс восприятия объектов действительности более подробно и попытаемся доказать, что центральный тип зрения выступает психофизиологической основой для структурно-семантического каркаса текста типа «описание».

Восприятие - это узнавание и формирование образа «физически присутствующего объекта» [Любимов, 2007, с. 106], возможное благодаря тому, что «в любом восприятии содержится память» [Тармаева, 2011, с. 15]. Известно, что около $80 \%$ информации о действительности человек получает с помощью зрительного анализатора, поэтому зрительное восприятие считается основным способом восприятия мира [Князева, 2009, с. 177; Тихонова, 2006, с. 19].

Психофизическая способность людей видеть окружающий мир обусловлена наличием зрительного анализатора. Зрительный анализатор состоит из нескольких отделов, основными из которых являются периферический (рецепторный) и центральный. В центральном отделе находится сетчатка - первый приемник всех световых волн и импульсов, где происходит «переработка, трансформация внешней световой энергии в биоэлектрический импульс нейрона» [Демирчоглян, 1997, c. 14]. В сетчатке имеется определенное количество нейронных звеньев, основным из которых выступает слой специальных фоторецепторов - палочек и колбочек. Фоторецепторы имеют разные характеристики, благодаря которым можно различать два разных типа зрения: центральный и периферический. Центральное зрение - это самый главный элемент зрительной функции человека [Делягин, 2007, с. 108]. Всю цветовую гамму, все разнообразие объектов действительности и их признаков (объем, размер, форму) можно наблюдать благодаря работе центрального отдела зрительного анализатора. За распознавание движения объектов в пространстве отвечает периферическое зрение [там же, c. 108]. Получается, что объекты в статике и в движении воспринимаются разными отделами зрительного органа и, соответственно, разными типами зрения.

Как утверждают психофизиологи, восприятие объектов обусловливается зрительными задачами. Первой зрительной задачей является обнаружение объекта, следующим пунктом идет отнесение данного объекта к соответствующему классу. На завершающем этапе восприятия объекта происходит его сопоставление с конкретным эталоном из когнитивной сферы человека [Прокопенко, 2006, c. 19].

Интересным представляется, что в работе зрительного анализатора по распознаванию признаков объектов прослеживаются определенные этапы. Это подтверждается гипотезой психофизиологов «об иерархической структуре процессов восприятия» [там же, с. 21]. Распознавание локальных признаков, характеризующих отдельные участки контура объекта, является первостепенной задачей центрального типа зрения. Следующей ступенью является восприятие таких признаков и свойств, благодаря которым можно охарактеризовать объект в целом. На данном этапе параллельно протекают мыслительные процессы по соотнесению увиденного объекта с его проекцией в когнитивном пространстве, то есть с его мысленным образом. На последнем этапе определяется степень качественного и количественного сходства объектов.

Известно, что воспринятая центральным типом зрения предметность пространства имеет один способ реализации языковыми средствами - актантным 
ядром описательного текста. В актантное ядро описания входят слова, называющие целое и его части (актант-холоним и актанты-партонимы) [Хамаганова, 2002, с. 22]. Иными словами, предметные характеристики окружающего мира, воспринятые центральным типом зрения, вербализуются в описательном тексте и составляют его структурно-семантическую основу [Смирнова, 2014; 2017, с. 56-57]. Отметим также, что в описании-портрете и в описании предмета находят свое отражение основные этапы зрительного восприятия признаков объектов.

В данной статье обратимся к рассмотрению примеров из поэмы Н. В. Гоголя «Мертвые души» и из романа Ч. Диккенса «Dombey and son». Актантное ядро описательного текста будем выделять подчеркиванием, жирным шрифтом отметим признаковые слова.

На бюро, выложенном перламутною мозаикой, лежало множество всякой всячины:: куча исписанных мелко бумажек...два пера, запачканные чернилами, высохшие, как в чахотке, зубочистка, совершенно пожелтевшая, которою хозяин, может быть, ковырял в зубах своих еще до нашествия на Москву французов.

Фрагмент вышеприведенного описания передает результат восприятия комнаты в доме помещика Плюшкина. Информация, вербализованная в описательном тексте, была получена центральным типом зрения. Доказательством этого являются структурно-семантические составляющие описания, которые могут быть восприняты именно данным типом зрения. Статичным воспринимаемым объектом в данном случае является старое бюро, находившееся в комнате и попавшее в поле зрения наблюдателя. Бюро выступает холонимом (главным актантом) данного описания, так как обозначает «целое». Актанты, номинирующие предметы, расположенные на бюро, (бумажки, перья, зубочистка), представляют собой предметные актанты-партонимы, то есть являются структурными составляющими наблюдаемого пространства. Данные актанты наделяются определенными признаками, которые сознание наблюдателя соотносит с признаками «конкретного эталона из когнитивной сферы человека» [Прокопенко, 2006]. Несоответствие наблюдаемых признаков объектов признакам идеального образца запускает процесс их иронического оценивания: перо - «как в чахотке», зубочистка - как будто ею пользовались «еще до нашествия на Москву франиу306».

Пример подтверждает, что в описании передаются именно те признаковые характеристики объектов, перцепция которых основана на работе центрального отдела зрительного анализатора. Признаки цвета и его оттенков (совершенно пожелтевщая, испачканные чернилами), признаки состава предметов (выложенный перламутною мозаикой), как известно, распознаются именно центральным типом зрения.

Далее подтвердим наши умозаключения примером на английском языке.

This celebrated Mrs. Pipchin was a marvelous ill-favoured, ill-conditioned old lady, of a stooping figure, with a mottled face, like bad marble, a hook nose, and a hard grey eye, that looked as if it might have been hammered at on an anvil without sustaining any injury». (Эта знаменитая миссис Пипчин была изумительно некрасивой, дурного нрава пожилой женщиной с сутулой фигурой, с пятнистым лицом, как плохой мрамор, крючковатым носом и тяжелым серым глазом, ко- 
С. И. Смирнова. Зрительное восприятие как психофизиологическая основа объекта текста типа «описание»

торый выглядел так, как будто по нему могли стучать молотком на наковальне, не причиняя никакого вреда).

В приведенном описательном тексте можно наблюдать языковое воплощение результата восприятия внешнего облика женщины. Данное описание отражает поэтапное восприятие объекта (миссис Пипчин) и основных его признаков. Восприятие осуществляется поэтапно, согласно задачам зрительного восприятия [там же, с. 21]: прежде всего, характеризуются общие признаки ее внешнего облика, а также фигуры (сутулая, некрасивая). Черты ее лица описываются более подробно, а именно признаками подобия, отражающими количественное и качественное сходство объектов. Данная особенность восприятия свидетельствует о том, что сравнение и оценка неотделимы друг от друга [Арутюнова, 1988, c. 204-216].

Особенности лица воспитательницы представлены в описании актантным ядром (lady, figure, face, nose, eye). Само лицо настолько пятнистое, что у наблюдателя возникает необычная ассоциация с некачественным мрамором; нос привлекает наблюдателя своей необычной формой крючка. Глаза миссис Пипчин описаны с гиперболическим сравнением, которое является актантнопризнаковым компонентом описательного текста. То есть в описательном тексте отражается не только процесс непосредственного восприятия объектов, но и результат протекающих одновременно с ним мыслительных операций по поиску признаков подобия. Это свидетельствует о восприятии признаков высшего уровня, завершающем процесс зрительного восприятия. Таким образом, и в данном англоязычном примере снова обнаруживаем языковое воплощение результата восприятия признаков объектов, наблюдаемых центральным типом зрения.

Из вышесказанного следует, что способом вербализации предметных характеристик, воспринятых центральным зрением, является описательный текст. Эмпирический материал делает очевидным вывод: в описательном тексте находит свое языковое воплощение результат психофизических процессов, протекающих в зрительном анализаторе. Это подтверждается структурносемантической основой описания - актантным ядром. Следовательно, центральный тип зрения можно правомерно считать психофизиологической основой объекта текста типа «описание».

\section{Литература}

1. Арутюнова Н. Д. Типы языковых значений. Оценка. Событие. Факт. М.: Наука, 1988. 345 c.

2. Делягин В., Абдулов Р., Мельникова М. Зрение и компьютер (страшилки и реальность) // Мир ПК. 2007. № 9. С. 102-108.

3. Демирчоглян Г. Как сохранить и улучшить зрение. Донецк: Сталкер, 1997. 320 с.

4. Князева, Е. А. Проблема восприятия: А. Бергсон и современная когнитивная наука // Логос, 2009. № 3(71). С. 173-184.

5. Любимов В. В. Из лекций по психологии восприятия // Вестник Московского госуниверситета. Психология. М: Эксмо, 2007. № 1. С. 104-118.

6. Нечаева О. А. Функционально-смысловые типы речи: автореф. дис. ... д-ра филол. наук. М., 1975. 46 с.

7. Прокопенко В. Т., Трофимов В. А., Шарок Л. П. Психология зрительного восприятия: учеб. пособие. СПб.: Изд-во СПбГУИТМО, 2006. 73 с. 
8. Смирнова С. И. Реализация иронии в констатирующих текстах «описание» и «повествование»: дис. ... канд. филол. наук. Улан-Удэ, 2014. 194 с.

9. Смирнова С. И. Психофизиология зрительного восприятия как основа объекта описания и объекта повествования // Вестник Бурятского государственного университета. 2017. № 3. C. 52-57.

10. Тармаева В. И. Когнитивная гармония как механизм интерпретации текста: автореф. дис. ... д-ра филол. наук. Кемерово, 2011. 47 с.

11. Тихонова Г. Н., Феоктистова Н. Ю. Кто как видит: зрительный анализатор: от одноклеточных до человека. М.: Чистые пруды, 2006. 32 с.

12. Хамаганова В. М. Структурно-семантическая и лексическая модель текста типа «описание»: проблемы семиотики и онтологии: дис. ... д-ра филол. наук. М., 2002. 332 с.

\section{VISUAL PERCEPTION AS PSYCHO-PHYSIOLOGICAL BASIS OF THE TEXT TYPE "DESCRIPTION}

\section{(c) Svetlana Ig. Smirnova}

Ph.D. of Philology, senior lecturer,

Buryat State University

16, Suhe-Batora Str., Ulan-Ude, 670000, Russia

E-mail: s.petenko@yandex.ru

The article is devoted to the study of psychophysiological basis of descriptive texts. The research reveals peculiarities of visual analyzer, the process of visual perception of objects. Furthermore, the article proves that the structure-semantic frame of descriptive text is relevant to the spatial parameters of objects of reality, perceived with central type of vision. The author considers the structure of the visual analyzer, namely the central and peripheral departments responsible for receiving different pulses from the outside world. The article reveals one of the features of objects perception by the central type of vision. It turns out that the central vision allows us to ascertain the presence of objects, to see their shape, size and color characteristics. Perceived by the central type of vision, the objectivity of the world is reflected verbally in the descriptive type of text with the actant nucleus as its structural and semantic framework.

Keywords: descriptive text; perception; visual analyzer; Central and peripheral vision; Central type of vision; photoreceptors; structural and semantic framework; object of speech; actant nucleus of the text; characteristic words. 